\title{
Evidence-informed physical therapy management of performance-related musculoskeletal disorders in musicians
}

\section{Cliffton Chan* and Bronwen Ackermann}

Discipline of Biomedical Science, Sydney Medical School, The University of Sydney, Sydney, NSW, Australia

\section{Edited by:}

David Wasley, Cardiff Metropolitan

University, UK

\section{Reviewed by:}

Lutz Jäncke, University of Zurich,

Switzerland

Christoff Zalpour, University of Applied

Sciences Osnabrueck, Germany

\section{${ }^{*}$ Correspondence:}

Cliffton Chan, Discipline of Biomedical

Science, Sydney Medical School, The

University of Sydney, 75 East Street,

Lidcombe, Sydney, NSW 1825,

Australia

e-mail: cliffton.chan@sydney.edu.au
Playing a musical instrument at an elite level is a highly complex motor skill. The regular daily training loads resulting from practice, rehearsals and performances place great demands on the neuromusculoskeletal systems of the body. As a consequence, performance-related musculoskeletal disorders (PRMDs) are globally recognized as common phenomena amongst professional orchestral musicians. These disorders create a significant financial burden to individuals and orchestras as well as lead to serious consequences to the musicians' performance and ultimately their career. Physical therapists are experts in treating musculoskeletal injuries and are ideally placed to apply their skills to manage PRMDs in this hyper-functioning population, but there is little available evidence to guide specific injury management approaches. An Australia-wide survey of professional orchestral musicians revealed that the musicians attributed excessively high or sudden increase in playing-load as major contributors to their PRMDs. Therefore, facilitating musicians to better manage these loads should be a cornerstone of physical therapy management. The Sound Practice orchestral musicians work health and safety project used formative and process evaluation approaches to develop evidence-informed and clinically applicable physical therapy interventions, ultimately resulting in favorable outcomes. After these methodologies were employed, the intervention studies were conducted with a national cohort of professional musicians including: health education, onsite injury management, cross-training exercise regimes, performance postural analysis, and music performance biomechanics feedback. The outcomes of all these interventions will be discussed alongside a focussed review on the existing literature of these management strategies. Finally, a framework for best-practice physical therapy management of PRMDs in musicians will be provided.

Keywords: physical therapy, playing-related musculoskeletal disorders, work-related musculoskeletal disorders, overuse, performing arts medicine, injury management, formative evaluation, process evaluation

\section{INTRODUCTION}

Performing music at an elite level requires greatly developed and integrated sensorimotor and neuromuscular body systems. These are honed by long daily hours of practicing highly complex movements over many years of intensive training (Watson, 2006; Hyde et al., 2009; Krause et al., 2010; Hoenig et al., 2011). As the musician progresses in their skills, the repertoire becomes increasingly challenging requiring more practice time. To then reach the epiphany of the music profession, these meticulous and artistic athletes persist with practice and work at a heightened level of physical stress, making them highly susceptible to neuromusculoskeletal injuries (Brandfonbrener, 2010).

Injury rates are globally reported to be high in this profession (Middlestadt and Fishbein, 1989; Leaver etal., 2011; Paarup etal., 2011; Ackermann etal., 2012), and are thought to relate to the repetitive physical loads reflecting the particular demands of the instrument played. For example, shoulder injuries occur frequently in violin and viola players (Leaver et al., 2011; Paarup et al., 2011; Ackermann et al., 2012), while orofacial and embouchure problems are common in brass players (Iltis and Givens, 2005; Fletcher, 2008; Frucht, 2009). The same phenomenon is observed in sport, whereby the injury region reflects the physical demands of the sport played. For example, shoulder problems are extremely common in swimmers, and knee and ankle problems frequently occur in soccer players (Pink and Tibone, 2000; Drawer and Fuller, 2001; Waivenhaus et al., 2012). Despite this similarity between the task-specific type of injury risks faced by musicians and athletes, there are clear differences in the provision of health education and injury management services.

Sports Medicine has made substantial progress in the monitoring of their athletes for the vigorous demands of their sport and early injury management through strong networks with sports medical and allied health professionals. In contrast, musicians usually have minimal connections with specialized performing arts healthcare professionals (Tubiana, 2000; Guptill, 2011). Throughout their training and professional life, musicians do not receive specialized health education and advice to aid in injury recovery 
or to minimize potential injury risks (Hoppmann and Patrone, 1989). Furthermore, musicians typically do not participate in other supplementary training activities to support their performance like the athletes. Upon reaching a professional level of performance, musicians usually cease to attend lessons or receive any technical feedback or instruction. This is unlike other elite performance domains, such as sports and dance, where this is maintained throughout their career. Increasing knowledge of healthy practice strategies and implementing tailored injury prevention measures specifically for musicians, following approaches similar to Sports Medicine, may reduce the susceptibility of musicians to a range of musculoskeletal disorders (Zaza, 1993, 1994; Tubiana, 2000).

In addition to exposure to physical injury risks, musicians, like other athletes, face intense psychological pressures arising from performing under public scrutiny. Unlike sports communities, however, negative cultural perceptions regarding injury within the musical community can provide a challenge to implementing a best practice model of healthcare (Rickert etal., 2013). Negative connotations of inferior technical competency are commonly directed at musicians suffering performance-related injuries by their peers (Guptill, 2011, 2012; Raymond et al., 2012). Injuries can thus be associated with feelings of professional inadequacy or shame (Bragge et al., 2006; Guptill, 2011; Chimenti etal., 2013), tending to lead to injury concealment behaviors that delay the implementation of appropriate healthcare management. Such stigmas associated with playing-related injuries, as well as the lack of specialized health services and education, have led to professional orchestral musicians' often playing through the pain until they can no longer manage (Schoeb and Zosso, 2012). Additionally, there is increasing awareness of the complex relationship between performance-related musculoskeletal disorders (PRMDs), performance-related pain and a range of psychosocial factors (Altenmüller and Jabusch, 2010; Kenny and Ackermann, 2013). Hence effective rehabilitation of musicians' injuries requires healthcare professionals to manage both the physical and psychological aspects of PRMDs (see Table 1). Healthcare practitioners should be aware of their potential contribution to psychosocial and cultural factors in the performing arts field, however, it is beyond the scope of this paper to explore the psychosocial interventions for PRMDs.

Physical therapists are trained to use scientific and evidencebased assessments and treatments to prevent musculoskeletal disease and disability, and are experts in optimizing function and performance (Kolt and Snyder-Mackler, 2007). As a profession trained to treat a wide range of neurological, respiratory and musculoskeletal conditions, they are well-positioned to apply their manual therapy, exercise and biomechanics skills to managing PRMDs in musicians (World Confederation for Physical Therapy, 2011). However, the pool of physical therapists treating musicians as a specialty is very small compared to sports physical therapy although this specialty appears to be growing. One of the challenges to current physical therapy management approaches is the lack of specialized training programs and available evidence on effective intervention strategies for musicians.

\section{USE OF FORMATIVE AND PROCESS EVALUATION METHODOLOGY}

The use of rigorous epidemiological approaches in the design and implementation stages of developing an occupation-specific prevention and management program may increase the likelihood of intervention outcomes being successful (Viera and Kumar, 2004; Stetler et al., 2006; Boocock et al., 2007; Jurg et al., 2008; Bell and Burnett, 2009; Harding et al., 2009). This was found to be the case in our studies with professional orchestral musicians (Chan et al., 2013b,c). All stakeholders including researchers, expert clinicians, orchestral management and musician employee representatives should contribute. Including all relevant parties in the development of prevention and management programs can help to avoid organizational or work barriers that may otherwise hinder trial compliance and participation rates (Dehar et al., 1993). Formative and process evaluation methodologies are increasingly being employed to ensure interventions are researched, designed and pilot tested prior to implementation (Stetler et al., 2006; Jurg et al., 2008; Baranowski et al., 2009), and suit the needs of designing interventions for the musician population.

In the first stage, formative evaluation strategies were utilized in the development of specific interventions for professional orchestral musicians to optimize likely positive outcomes (Chan et al., 2013b,c). A comprehensive literature review of musicians' health, as well as a review of relevant literature from occupational and sports medicine was undertaken and information synthesized to draft a preliminary program. A panel of experienced physical therapists reviewed the proposed intervention programs and were asked for their evaluation and comments. Musicians and their management teams were also asked to give feedback about the proposal. In instances where there was a lack of consensus, the program was revised, and subsequently sent out for feedback. Working closely with orchestra management staff was necessary for the programs to be designed in a way that was compatible with the context and practicalities of the orchestral environment and schedules. This formative evaluation process was vital in ensuring the interventions were highly credible and likely to optimize desired results.

In the pilot testing or process evaluation phase, interventions were trialed and modified as necessary based on evaluation of the intervention by the researchers, feedback from the physical therapists involved in the study as well as feedback from a small number of musicians that had volunteered for the pilot trial. While these physical therapists were highly experienced and qualified in sports and occupational physical therapy, most did not have musician-specific injury management expertise. This stage of the program development had the additional benefit of allowing participating physical therapists to familiarize themselves with the research protocol and intervention delivery. The piloting process was also useful in refining the intricacies of implementing the intervention and identifying potential impracticalities or errors that may occur when implementing the program on a larger nationwide scale. Therefore, formative and process evaluation provided an effective means to develop intervention trials that had good support from all relevant stakeholders at the outset of the project. 
Table 1 | Physical and psychosocial factors influencing the development and perpetuation of performance-related musculoskeletal disorders (based on Wu, 2007; Altenmüller and Jabusch, 2010; Brandfonbrener, 2010; Leaver et al., 2011; Ackermann et al., 2012; Kenny and Ackermann, 2013).

\begin{tabular}{|c|c|c|}
\hline \multicolumn{2}{|c|}{ Physical risk factors } & \multirow[t]{2}{*}{ Psychosocial risk factors } \\
\hline Non-modifiable & Minimally modifiable or modifiable & \\
\hline $\begin{array}{l}\text { - Instrument played } \\
\text { - Anthropometrics } \\
\text { - Gender } \\
\text { - Playing conditions - temperature, length } \\
\text { of rehearsals and performances } \\
\text { - Joint laxity - past trauma or generalized } \\
\text { - Challenging repertoire }\end{array}$ & $\begin{array}{l}\text { - Overload - sustained high levels of } \\
\text { playing or sudden increases in playing } \\
\text { - Lack of rest breaks in rehearsals and } \\
\text { private practice } \\
\text { - Poor posture } \\
\text { - Poor biomechanics } \\
\text { - Joint hypomobility } \\
\text { - Instrumental technique and pedagogical } \\
\text { style } \\
\text { - Lack of physical conditioning } \\
\text { - Poor injury management }\end{array}$ & $\begin{array}{l}\text { - General and/or performance anxiety } \\
\text { - Depression } \\
\text { - Pressures from self, peers, educational } \\
\text { institution or work organization } \\
\text { - Work and/or non-work Related stress } \\
\text { - Social phobia } \\
\text { - Personality traits - e.g., somatization } \\
\text { tendencies, extreme perfectionism }\end{array}$ \\
\hline
\end{tabular}

The purpose of this review is to inform physical therapists of evidence-based management strategies for PRMDs in the musician population that can be readily implemented in the clinic environment and introduced into music institutions and organizations. The outcomes of a series of formative and process evaluated intervention strategies, undertaken as part of the "Sound Practice" project, along with their clinical and research implications will be presented. These include: health education and advice provided to musicians, specialized onsite injury and recovery services, exercise regimes, and postural and biomechanics analysis.

\section{RESULTS}

\section{MUSICIAN'S HEALTH EDUCATION AND ADVICE}

It is generally accepted that a vital component in the prevention and management of work-related musculoskeletal disorders is appropriate health education and medical advice (Bohr, 2002; Silverstein and Clark, 2004). Since professional musicians often endure long rehearsals and performances that involve extremely repetitive activities, it is only sensible to educate them about potential risks to which they may be exposed; since these could lead to them sustaining a work-related injury (Pascarelli and Hsu, 2001; Baldwin, 2004; da Costa and Viera, 2010). For example, some modifiable risk factors associated with PRMDs on which physical therapists could provide advice are: scheduling of private practice sessions, rest and relative rest after injury, basic nutrition and hydration, general fitness and early injury identification and management. However, at present there is a lack of formal health and fitness education during musical training as well as within the orchestral workplace (Barrowcliffe, 1999; Tubiana, 2000; Dommerholt, 2009). Musicians' lack of understanding of injury causes or best management approaches may lead to musicians using unreliable sources for health advice, and therefore poor or inadequate management of injuries. Physical therapists working with professional musicians should be able to provide specialized and relevant healthcare advice to promote optimal injury prevention strategies and management enabling musicians to safely sustain their necessarily highly repetitive playing loads.

Throughout the duration of the "Sound Practice" project each of the Australian state orchestras received regular delivery of healthcare education, covering physical, psychological, nutritional and auditory health topics. Informal feedback following these sessions indicated the musicians felt they had a high need for this education, and should have received it much earlier in their musical careers.

\section{Private practice scheduling}

The importance of planning out private practice for the prevention of PRMDs is suggested by various authors (Zaza, 1994; Green et al., 2000). Even professional musicians may not consider that challenging and higher intensity repertoire should be practiced in shorter durations with frequent rest breaks or with easier repertoire in between (Fry, 2000) to avoid muscle fatigue. While professional orchestral musicians often have limited flexibility in their private practice schedule, wherever possible, distributing the total private practice schedule through the day (Green et al., 2000) will ensure that there is adequate rest and recovery for the body, and allows for better skill refinement and consolidation (Donovan and Radosevich, 1999; Robertson et al., 2004; Lee and Wishart, 2005).

When the amount of playing hours fluctuate due to performances, auditions and other playing demands, musicians should be made aware of the potential overload on musculoskeletal structures. Such a problem is often caused by sudden increases of overall playing load and musicians should adjust their practice schedules accordingly (Newmark and Lederman, 1987; Davies and Mangion, 2002; Ackermann and Adams, 2004). During periods of increased load, a higher number of performances and 
rehearsals, musicians may need to reduce physical practice and employ the use of practice strategies such as shadow-playing or mental practice (Menuhim, 1986; Keller, 2012). In the opposite situation, after periods of minimal playing (i.e., during holidays), musicians should build up their intensity and duration of private practice prior to returning to full playing workloads (Green et al., 2000). In summary, orchestral musicians should carefully plan their private practice schedules as well as monitor their overall playing load to minimize the potential for development of PRMDs.

\section{Rest and relative rest after injury}

Rest breaks to prevent work-related musculoskeletal disorders, especially injuries relating to overuse as is typical in professional musicians, are important in all occupations involving long periods of repetitive work (Huang and Feuerstein, 2004). In occupational medicine literature, it is recommended that regular breaks be taken, a minimum of 5 min every hour, to prevent excessive physical stress and allow energy stores in the muscles to be replenished (Westgaard and Winkel, 1996; Silverstein and Clark, 2004; Kennedy et al., 2010). For musicians, frequent and regular breaks assist in reducing the constant strain and load-bearing on the joints, as well as allowing recovery of supporting musculature and fine-control muscles of the fingers and lips (Zaza, 1994). While musicians may have little control over rest breaks during orchestral rehearsal and performance, they should be able to appropriately implement these in their private practice sessions.

There is evidence to suggest that taking regular breaks during private practice has a protective effect on recurrent PRMDs in musicians (Zaza and Farewell, 1997). As a general recommendation, a 5-min rest break should be taken for every $25 \mathrm{~min}$ of playing (Zaza, 1994; Robinson and Zander, 2002; Ackermann, 2010). Musicians should also take into consideration more frequent breaks when practicing repertoire with higher intensity and increased difficulty. If practice sessions are longer, 10-15 min rest should be taken after 45-60 min (Robinson and Zander, 2002; Ackermann, 2010). Musicians should be acutely aware that working at sustained elevated physical-stress levels is damaging to musculoskeletal structures and without adequate rest the tissue breakdown process will exceed the speed of repair ultimately leading to injury (Kumar, 2001).

Following an injury, it is important that the musician understand the basic healing characteristics of the relevant body tissues to ensure good compliance in rehabilitation protocols (Ackermann, 2010; Hoppmann, 2010). In the event of acute musculoskeletal injury, it is recommended that tissues should be given a rest period of between 3 and 7 days to optimize the initial inflammatory phase (Kannus et al., 2003; Järvinen et al., 2007). To facilitate optimal tissue healing and integrity and prevent further tissue atrophy the rest period should be followed by gentle and graduated range of movement exercises depending on the severity of tissue damage (Popovich et al., 2000; Orchard and Best, 2002; Kannus etal., 2003; Nash et al., 2004). For the injured musician, shorter practice sessions with more regular breaks may be necessary in the early injury recovery phase (Norris, 1993), for example $5 \mathrm{~min}$ playing followed by $5 \mathrm{~min}$ rest.
As symptoms subside and the injury heals, the number of playing sessions and their duration can be progressively increased to match ability. Rehabilitation should be directed toward functional recovery from the outset as in other specialized domains, aiming for graduated return to work from about week six following the injury, depending on the injury severity (Järvinen et al., 2007). Orchestral musicians may otherwise return to performance prior to adequate healing and thereby risk ongoing health issues.

\section{Nutrition and hydration}

It would seem logical that nutrition and hydration are important considerations in a musicians' preparation before their long practice sessions and performances much like the athletic population. A musician's nutritional needs are likely to be above that of the general population due to the physical nature of their work over long periods suggesting nutritional education should be included in the prevention and management of PRMDs (Robinson and Zander, 2002; Shafer-Crane, 2006).

In low intensity endurance activities, approximately $60 \%$ of the energy expended comes from carbohydrate sources (Holt, 1993; Manore etal., 2009). This would suggest that before rehearsals and performances, a musician's diet should include carbohydrates, then fats and proteins. Low to medium glycemic index (GI) carbohydrates, i.e., energy sources that produce a slow to moderate rise in blood glucose and insulin, would be likely to be the most ideal to enable the energy to be sustained over long rehearsals and performances (Manore et al., 2009). Fat and protein sources provide approximately 25 and $15 \%$ respectively of the energy supplies during low intensity endurance activity (Holt, 1993; Manore et al., 2009). Following long performances, consuming a more rapid release carbohydrate food source (medium to high GI) as well as proteins are suitable to optimally replenish depleted fuel reserves and to facilitate repair of any muscle fiber breakdown that may have occurred (Phillips, 2006; Campbell et al., 2007; Kumar et al., 2009; Manore et al., 2009). Sports science research indicates it is important to consume these carbohydrate and protein food sources within one hour after the activity (Campbell et al., 2007). Therefore, an adequate nutritional intake before and after strenuous rehearsals and performances may be important in potentially reducing the risk of PRMDs (Phillips, 2006; Campbell et al., 2007).

Another important component of nutritional consideration is water intake, with these needs varying from approximately 21 of water per day for a sedentary adult male under normal environmental conditions up to approximately 31 with the addition of modest physical activity (Kenefick and Sawka, 2007; Jéquier and Constant, 2010; Popkin etal., 2010). To maintain hydration in a warmer environment, water intake may need to be further increased to account for the greater fluid loss through sweat. If musicians become too dehydrated prior to performances, this could lead to tiredness, muscular weakness, dry and sticky mouth and tongue, headaches, dizziness or lightheadedness (Jéquier and Constant, 2010), which could potentially affect playing. Musicians who regularly perform under different environmental conditions both indoors and outdoors should be mindful of their water intake; replenishing before, during and 
after playing as required (Kenefick and Sawka, 2007; Montain, 2008). Even a small degree of dehydration can affect cognitive and physical function (Shirreffs, 2009; Popkin et al., 2010), and as such musicians needing to perform at their peak and reduce the likelihood of injury should be aware of their water intake.

\section{General fitness}

Participation in cardiovascular fitness and resistance training has been suggested to be an important element in maintaining a healthy and long career in the performing arts (Shafer-Crane, 2006). There are many physical and psychological benefits associated with appropriate levels of regular physical activity, such as significant increases in cardiovascular fitness, skeletal muscle endurance, reaction time, and decreased incidence of osteoarthritis, depression and anxiety (Booth et al., 2012). In one previous survey, musicians who performed physical activity regularly rated their perceived exertion level during rehearsal to be significantly lower than musicians that did little or no physical activity (Wilke et al., 2011).

Musicians, like other hyper-functioning performers such as dancers and athletes, should undertake both cardiovascular and resistance exercises each week to best achieve and maintain optimal physical conditioning. Based on recommendations from the American College of Sports Medicine (Medicine ACoS, 2010) and expert music health practitioners (Ackermann et al., 2002; Ackermann, 2010; Wilke et al., 2011), an example of a potential best-practice exercise guideline for musicians is included in Table 2 below including the type, frequency, and duration of exercises.

Specialized and tailored musician exercise programs may further enhance physical condition of performers without overloading already heavily worked structures, and these will be discussed in Section "Cross-Training Exercise Regimes" below.

\section{Early injury identification and management}

Early identification of injury and commencement of rehabilitation is key to optimizing prognosis of most neuromusculoskeletal problems (Linton, 2002; Gatchel et al., 2003; Stucki et al., 2005), with potential benefits to professional orchestral musicians (Milanese, 2000). Not only can the best healthcare management be immediately implemented when injury presents (Orchard and Best, 2002; Dommerholt, 2010; Pemoff et al., 2012), but secondary problems can also be prevented (Laisné et al., 2012). For musicians, early injury identification or triage by an onsite physical therapist could minimize the effect of the injury on playing/performance by immediately implementing a plan for best injury management (Chan etal., 2013c), thus aiding a more rapid return to work or play (Shafer-Crane, 2006). Musicians should be educated on the principles of first aid that can be applied prior to a healthcare consultation for acute injury management. The principles of first aid could include: resting the injured area, icing the injured area, and applying compression with elevation in the presence of swelling and seeking a diagnosis if symptoms persist (Australia SJsA, 2012; Bruckner and Khan, 2012).

For musicians, receiving immediate and specific advice when to simply rest and self-manage a mild strain or when to consult a health professional for an injury is likely to be important for optimizing recovery.

\section{SPECIALIZED ONSITE INJURY AND RECOVERY SERVICES}

A brief intensive physical therapy-led triage service for professional orchestral musicians was successful in managing musicians' injuries during a busy playing period (Milanese, 2000). This author concluded that the availability of a regular triage service may allow earlier identification and management of PRMDs occurring throughout the usual playing schedule. Such an acute injury management advice service, led by physical therapists, was developed and implemented for 12-weeks for each state orchestra Australia-wide (Chan et al., 2013c). In consultation with orchestral management, clinics were held for one hour every fortnight, usually during the lunch hour between rehearsal calls, with both an anonymous appointment booking system or drop-in services available.

This onsite triage service was well-received by the musicians, and was evidenced by consistent feedback of the musicians' gratitude toward having such an easily available injury management service. Most of the consultations at these triage services were classified as PRMDs, and services were more likely to be utilized by females and string players. Most musicians who presented with PRMDs reported that these affect their normal playing, and the physical therapists considered that the majority of conditions seen may have been preventable. These encouraging results support the regular accessibility of a triage clinic at orchestral premises; if this is achievable in the longer term it may be possible that many PRMDs could be better managed or prevented altogether.

Following on from the injury advisory service, an intensive trial providing both injury advice and short treatments (usually recovery massage) were undertaken with one orchestra. This orchestra's management team forecasted a possible increase in playing-related injury due to a heavier than normal orchestral cycle immediately following a holiday period. In this study of short recovery treatments and injury advice, 10 to $15 \mathrm{~min}$ consultations with a qualified massage therapist and/or physical therapist were made available throughout the duration of the orchestral season. Feedback from musicians and orchestra management indicated that most musicians benefited from these sessions. Additionally, shorter sessions of lighter "effleurage and petrissage" style massage (Weerapong and Kolt, 2005) were preferred over the occasional more intensive massage or treatment approaches as the latter tended to leave some soreness effects in the next playing session. Management reported far less absences than they had anticipated over the course of the trial. These quick recovery treatments may be greatly beneficial to musicians during busy playing periods, or during intensive touring programs (Ackermann, 2002).

\section{CROSS-TRAINING EXERCISE REGIMES}

Despite suggestions that purpose-designed exercise regimes may play a major preventative role in avoiding PRMDs (Zaza, 1994; Brandfonbrener, 1997; Foxman and Burgel, 2006), there is a lack of clinical trials in this area for professional orchestral musicians. In other occupational health literature, there is a strong body of literature indicating the efficacy of exercise therapy in targeting work-related musculoskeletal disorders, especially in the 
Table 2 | An exercise guideline for musicians to improve cardiovascular fitness and muscular conditioning.

\begin{tabular}{|c|c|c|}
\hline Type of exercise & Frequency and duration & Example exercises \\
\hline Cardiovascular (aerobic) fitness exercise & $\begin{array}{l}\text { Five sessions of moderate intensity exercise per } \\
\text { week, at least } 30 \text { min per session or three } \\
\text { sessions of high intensity exercise per week, at } \\
\text { least } 20 \text { min per session }\end{array}$ & $\begin{array}{l}\text { Brisk walking, cycling at an easy pace, swimming } \\
\text { leisurely, or jogging, cycling with a slight incline or } \\
\text { low resistance, swimming with a moderate effort }\end{array}$ \\
\hline Resistive (muscular endurance) exercise & $\begin{array}{l}\text { Two sessions per week, } 2-3 \text { sets of } 10-20 \\
\text { repetitions, with } 90 \text { s rests in between sets } \\
\text { Aim to target 8-10 major muscle groups each } \\
\text { week }\end{array}$ & $\begin{array}{l}\text { - Scapular retractors (seated rows, reverse flyes) } \\
\text { - Shoulder external rotators } \\
\text { - Low back extensions } \\
\text { - Hip extensions (bridging in supine lying) } \\
\text { - Leg press, squats, or lunges } \\
\text { - Tricep extensions } \\
\text { - Bicep curls, push ups, chest press* }\end{array}$ \\
\hline
\end{tabular}

*Should be performed less regularly as the muscles used in these exercises are commonly tight and overused from instrumental playing.

neck, lower back and upper body regions (Boocock et al., 2007; Blangsted et al., 2008; Gerg and Smith, 2008; Äng et al., 2009; Bell and Burnett, 2009; Machotka et al., 2009; Andersen et al., 2010a,b; Lysaght et al., 2010). Purpose-designed exercise programs appear to be equally effective or better at reducing pain and improving functional outcomes in a cost-effective manner than a wide range of manual therapy or ergonomic interventions (Verhagen etal., 2007; van Eijsden etal., 2009). For these reasons, it is worth thoroughly investigating the efficacy of participation in tailored exercise programs for the professional orchestral musician population.

To guide the development of a specific exercise program for professional orchestral musicians a review of the existing literature was performed. Only one intervention trial was found that investigated the effects of a 15-week exercise program on PRMD levels and associated risk factors in a small sample of 17 professional orchestral musicians (de Greef et al., 2003). The intervention did not specifically evaluate exercise, but it was part of an intervention package of musician-specific education, some specific exercises and a traditional general strengthening exercise program. These authors found significant reductions in PRMD levels and self-reported improvements in playing-related posture, strength, fatigue, anxiety and ability to cope with work-related stress. Three other studies investigated the effect of exercise programs on university music students. Exercise interventions included resistance, core stability or aerobic exercises and were reported to reduce the presence, frequency and intensity of PRMDs and to improve instrumental playing posture (Spahn et al., 2001; Ackermann etal., 2002; Kava etal., 2010). It appears that simply participating in generic aerobic and strengthening fitness programs that provide overall cardiovascular and strength benefits are insufficient to prevent PRMDs or improve instrumental performance in musicians (Van Hees, 1997; Zetterberg et al., 1998). These findings from the four exercise trials suggest that there is a key role for developing exercise programs to target and potentially prevent PRMDs in professional musicians (Andersen et al., 2008).
The intervention groups participating in an exercise program targeting specific body regions susceptible to injury in musicians reported positive benefits in relation to PRMDs, exertion and a range of playing-related factors (Chan et al., 2013b). The literature on common body regions of PRMDs experienced by musicians was used to identify target regions for strengthening (Roset-Llobet et al., 2000; Wu, 2007; Leaver et al., 2011; Paarup et al., 2011; Ackermann et al., 2012). Existing evidence from sports and occupational health literature and well-accepted clinical practice was integrated to produce a progressive exercise program aimed to increase the endurance of supportive musculature in the shoulder, neck, abdominal, lower back, and lumbo-pelvic regions (Chan et al., 2013b). In addition, the exercises incorporated improving motor control and movement patterning of the body region. Participants were taught how to activate weakened stability muscles and then incorporate these muscles in a task-specific and functional manner for musicians.

Exercise programs targeted toward strengthening the supportive musculature of commonly injured areas in musicians were effective in reducing PRMDs and improved numerous other playing-related factors. The evaluation of survey results from the DVD exercise trial was greatly encouraging. A statistically significant reduction in PRMD frequency and severity occurred immediately after the 12-week intervention (Chan et al., 2014a). In the face-to-face exercise intervention study similar positive benefits were seen. Additionally, the opposite was observed in the control group's PRMD frequency and severity scores, which increased over the time of two standard orchestral cycles despite most of them undertaking regular physical activity (Chan etal., 2014b). After the cessation of the intervention at six-month follow-up, the beneficial effect seen in the intervention group slowly declined. This slight decline in positive effects of exercise is consistent with other literature documenting that exercise levels must be maintained for ongoing benefits (Kay et al., 2005; Fransen and McConnnell, 2008; Macedo etal., 2009; Vina etal., 2012). Participants of the interventions also reported moderate to high perceived improvements 
in the strength of the muscles that support their playing, flexibility, posture and ease of movement after the interventions, with most of these benefits maintained at similar levels at follow-up. The program appeared to be safe, with no injuries incurred as a direct consequence of the exercises. Therefore, it appears that musicians benefit from undertaking targeted exercises for muscles that support their instrumental playing demands and then to maintain such a program to prevent or manage PRMDs.

The ability of musicians to consistently participate in exercise programs was identified as a challenge by both orchestral management and musicians due to the continued variability in their work schedule. Programming of such sessions was an important and often complicated component that has to be factored into the successful implementation of such an intervention. By undertaking face-to-face exercise classes immediately before or after orchestral rehearsals and ensuring exercises focused on supporting rather than playing musculature, participants were still able to begin their rehearsal without any complaints of muscular fatigue affecting performance (Chan et al., 2014a). An additional solution suggested in the sports and rehabilitation medicine domains was to deliver an exercise program via the use of digital media (Hupperets et al., 2009; Vandelanotte and Mummery, 2011; Khalil et al., 2012). Such a flexible delivery method may increase accessibility, and allow more self-conscious musicians to participate without the scrutiny of their peers. Consequently, with the assistance of a professional film crew, the authors (CC and BA) produced an exercise DVD based on the program outlined in Chan et al. (2013b). The DVD study had a much higher initial uptake across all orchestras, although tended to be more popular with the musicians who had an existing physical activity regime (Chan et al., 2014a), suggesting that face-to-face classes are still also useful for musicians who perhaps feel they need more guidance and supervision. Through careful scheduling of the exercise class around rehearsal times and different forms of intervention delivery modes, barriers to attendance could be overcome.

\section{PERFORMANCE POSTURE ANALYSIS}

Correct posture has been defined as the body position adopted that loads the joints safely, helps conserve energy and allows freedom of movement (Kendall et al., 1952). Throughout instrumental playing, such a correct posture needs to also allow supportive muscles to sustain efficient static or dynamic movements and stability of the joints during performance actions. However, achieving optimal posture while performing can challenge basic concepts of "ideal" posture as playing most musical instruments requires maintaining asymmetrical postures in either sitting or standing over prolonged periods of time (Cailliet, 1990; Haslegrave, 1994; Nyman et al., 2007; Claus et al., 2009; Edling and Fjellman-Wiklund, 2009; O'Sullivan et al., 2012). Non-ideal postures requiring higher levels of muscle activation to support the musician and their instrument while compensating for reduced balance and control, may increase static loading and stress of neuromusculoskeletal structures, leading to earlier muscular fatigue and excessive muscular tension, creating a higher risk of developing PRMDs (Magnusson and Pope, 1998; Medoff, 1999; Kapandji, 2000; Tubiana, 2000; Kumar, 2001; Quarrier and Stenback, 2002; Price and Watson, 2011).

When maintaining postures for extended periods of time, such as sitting which is common to all orchestral musicians, spinal structures may be in non-ideal positions and muscles may become overloaded (Hedman and Fernie, 1997; Briggs et al., 2007). The effect of these postures on loading is further compounded by the added dynamic and asymmetrical stressors of playing their instrument (Hides, 2004; Briggs et al., 2007). The accumulation of these factors may accelerate degenerative processes in spinal motion segments and contribute to the development of dysfunction and pain (Kendall et al., 1952; Eijsden-Besseling et al., 1993; Hoogendoorn et al., 2000; Briggs et al., 2007; Price and Watson, 2011). Hence, maintaining as neutral and yet supported posture as possible may be important to prevent PRMDs in professional orchestral musicians.

Not only are sustained and poor postures a potential cause of injury to musculoskeletal structures, such postures could also potentially affect the neuromuscular system leading to an inferior musical performance. Posture also plays a crucial part in breathing mechanics, suggested to influence the volume and quality of sound produced by woodwind and brass instrumentalists (Quarrier and Stenback, 2002; Gaunt, 2004; Ackermann, 2010). In the general population, slouched posture has been shown to increase respiratory effort, and significantly decrease breathing capacity and control (O'Sullivan et al., 2002; Landers et al., 2003), with likely altered abdominal and accessory respiratory muscle recruitment patterns, as well as non-optimal biomechanical positioning of these muscles (Roussos, 1985; Kera and Maruyama, 2005; Ainscough-Potts et al., 2006; Ratnovsky et al., 2008). Such changes may have a negative impact on breathing endurance and control for musicians, although more research is needed in this area.

In order to test the impact of postural changes on instrumental playing, it was important to first ascertain whether clinically utilized methods of assessment were a reliable way of measuring and monitoring postural change. A postural trial was undertaken to determine whether experienced observers, including healthcare professionals and music educators with Alexander Technique/Body Mapping training, were able to detect postural changes in musicians from photographs following a 10-week exercise intervention program. This qualitative approach was tested because health professionals commonly use anterior and lateral photographic views of posture as part of their re-assessment of intervention effectiveness. Our results suggest that both health professionals and music educators were statistically significantly better $(p<0.001$ and $p=0.002$ respectively) than chance at selecting the true post-intervention photograph (Chan et al., 2013a). Although the health professionals $(66 \%)$ were slightly better than the music educators $(60 \%)$ at selecting the true post-intervention as having better posture, this result was not statistically different. Interestingly, $97 \%$ of the musician participants $(n=57)$ in this trial reported a noticeable improvement in their playing-related posture, which may reflect the limited ability for static photographs to evaluate dynamic postural changes and underlying muscular tension changes perceived by the professional orchestral 
musicians. While the use of static photographs may be useful in observing large scale abnormal skeletal postures, such as spinal deviations, forward head postures and shoulder angles (O'Sullivan etal., 2012), more subtle changes in a musician's technique and posture may suit other assessment methods such as videography. Nonetheless, the use of photographs may still provide a useful component of the re-assessment of a musician's posture by experienced health practitioners and music educators.

\section{MUSIC PERFORMANCE BIOMECHANICS FEEDBACK}

The term "biomechanics" refers to the study of internal and external forces acting on the human body and the effects produced by these forces (Freivalds, 2011). In occupational biomechanics, the physiological loads and stresses placed on the human body as a result of work-related tasks are analyzed (Chaffin et al., 1991). This can provide useful insights for physical therapists to help musicians optimize playing-related posture, maximize playing technique efficiencies, understand the importance of ergonomics and use of equipment, and potentially minimize unnecessary load on body preventing injury (McGinnis, 2013). Biomechanical analysis has also been applied extensively to sports performance, and in collaboration with coaches has led to new advances and insights into performance optimization and injury prevention. The term "Music Performance Biomechanics" is used here to extend this concept to the study of the mechanics of human movement applied to musical performance.

Whilst laboratory based quantitative research on music performance biomechanics is continuously emerging (Visentin et al., 2008; Chadefaux et al., 2012; Fernandes and de Barros, 2012; Kelleher et al., 2013; Sung et al., 2013), music teachers still rely almost entirely on qualitative approaches to performance technique feedback. This is mostly based on the outcome goal of the quality of sound output rather than observing how the musician is moving and reacting to achieve the desired sound. Even with the far greater amount of technological data regarding the athletic performer, there is little evidence as yet on how to best utilize such information to provide effective feedback in performance situations (Phillips et al., 2013). A qualitative approach is typically used in the practical sport setting, whereby movements and elements of technique are analyzed and then remediation occurs through feedback to address any identified flaws that may detrimentally affect performance or increase the risk of injury (Lees, 2002). Experts consider that observing the movements of the performer with their instrument is a key part of health assessment of the musician (Blum, 2003). Despite this, developing reliable rating scales for observing musicians playing their instrument has provided only limited success, with complicated systems showing poor inter-rater reliability (Ackermann and Adams, 2004), and simpler analyses showing better reliability (Driscoll and Ackermann, 2012). In such a domain where sound quality is the primary goal and playing styles can be diverse, it seems sensible to take a collaborative approach incorporating the expertise of the musician and the healthcare professional in achieving the goal of improving both sound and movement quality during performance.
The aim of the biomechanics feedback study as part of the "Sound Practice" project was to videograph performers in their usual rehearsal situations, identify those actions that may create a higher risk of physical strain within an individual musicians' technique, and then discuss the footage and analysis with the performer. The approach of providing individualized biomechanics feedback aimed to incorporate strategies is suggested by current research, whereby feedback needs to be task and person specific and the key elements that may benefit from remediation being readily modifiable (Phillips et al., 2013). The use of observation offers a chance to process performance information that could not occur simultaneously with physical practice, facilitating refinement (or maintenance) of complex motor skills (Wulf et al., 2010). In sports medicine literature, immediate feedback has been shown to enhance athletic task performance (Argus et al., 2011). By providing immediate feedback of the musician's performing as well as using the experience and skills of the musician themselves in the process, may then further improve the ability to adapt recommendations into an individual technique and optimizing musical performance.

- This biomechanics feedback procedure was further refined using process evaluation by piloting methods of feedback with an orchestra not involved in the "Sound Practice" project. Semistructured interviews post-feedback were used to further refine the amount of feedback given and presentation of footage and other information. 60 musicians volunteered to participate in this trial from the five orchestras who responded to the research invitation. Four out of these five orchestras requested a repeat of the trial in response to positive feedback from the musicians. A simple postfeedback survey was used to evaluate the trial, ranging from -5 for negative impact to +5 for positive impact. Of the $50 \%$ of musicians who responded to the survey, every response was neutral or positive in terms of impact on performance. The self-report factors included: ease of playing; effect on pain; muscle tension; understanding playing actions; impact on playing posture; impact on muscle fatigue; and impact on playing biomechanics. A narrative section allowed musicians' to write any additional responses, and these reinforced the positive outcome of this intervention and the strong engagement by the musicians in the process. Overall, this final biomechanics feedback trial was welcomed and supported by the orchestra management and the musicians themselves, and appeared to be a proactive way of monitoring performance and preventing injury.

While more research is needed in this field, along with exploring methods of integrating qualitative and quantitative data, preliminary results are encouraging and reinforce the need for physical therapists to consider music performance biomechanics as a component of their health management of the musician.

\section{RECOMMENDATIONS FOR EFFECTIVE PHYSICAL THERAPY MANAGEMENT OF PERFORMANCE-RELATED MUSCULOSKELETAL DISORDERS IN MUSICIANS}

Current approaches to the management of PRMDs have been based on expert opinion (Zaza, 1993; Shafer-Crane, 2006; Dommerholt, 2009, 2010) and translational research adapted from other fields of medicine. However, as guidelines for practice emerge based on new research findings (Altenmüller and Jabusch, 
2010; Driscoll and Ackermann, 2012) physical therapists should aim to adapt and modify their practice using such guidelines to enhance their management of PRMDs in musicians.

At all stages of physical therapy interventions for musicians' injuries, from prevention to assessment and onto rehabilitation, the performer must be regarded as a highly trained and skilled individual. Our own approaches to management need to be expanded and specialized to better meet the needs of the musician population. During history taking, the musician's background of years of playing, stage of skill, practice habits, teacher and "school of playing" should be recorded as these may influence their playing technique and posture. This information can add valuable perspectives for why the musician is adapting postures that may place them at a biomechanical disadvantage or provide indications to the mechanism of injury. During the physical examination, musicians must be examined with their instrument and with attention to the extreme ranges of motion related to performance requirements (Driscoll and Ackermann, 2012). A summary of some of these important information specifics to assessment and treatment of musicians is illustrated in Table 3.

Physical therapists should carefully structure the musicians' rehabilitation program to include musician specific education and advice, targeted exercise regimes and any other intervention strategies to achieve better functional outcomes. After an injury, musicians should be informed of the need to implement

Table 3 | Management of the injured musician.

Assessment
History
- Years of playing on primary instrument
- Stage of skill on primary instrument
- Increased switches between instruments or recent change of primary
instrument
- Current and past teacher/s
- "School of playing"
- Total playing hours (the sum of private practice, rehearsals and
performances)
- Preparation routine
- Practice schedule (e.g., 1 h, twice per day) and the duration and frequency
of rest breaks
- Changes to repertoire (e.g., style, difficulty)
- Any recent modifications to instrument (e.g., ergonomic devices) or playing
technique
- Impact of pain on current playing capacity
- Obsical examination

- Observation of static posture (with and without instrument) and playing posture

- A "Performance Postural Analysis" of the musician with and without instrument in sitting and standing should be performed. Poor postural habits are often missed if not performed under playing conditions (e.g., forward head posture when trying to seal their embouchure with the interface of the woodwind/brass instrument). Ideally this should be done with videography but photographs can also be used for more gross postural issues.

- Measure available range of movement at the injured joint to ensure there is sufficient range for the instrumentalist (e.g., $99^{\circ}$ of supination at left elbow in violin players, left hand span larger than right hand span in cello and double bass players).

- Test muscle strength and control of supporting muscles relevant to their instrumental playing and problem (e.g., string player with shoulder issue test external rotator cuff versus internal rotator cuff strength)

\section{Treatment}

\section{Education and advice}

- Private practice scheduling

- Rest and relative rest after injury

- Nutrition and hydration

- General fitness

- Early injury identification and management

Specialized onsite injury and recovery services

- Music organizations and music educational institutions should consider implementing such a service to ensure musicians received specialized advice on the best course of action for any concerns and injuries, as well as immediate management by suitably experienced healthcare professionals.

\section{Cross-training exercise regimes}

- Musicians should undertake a targeted exercise program for any existing postural concerns or identified problems, and for strengthening supportive musculature required for their instrument.

\section{Music performance biomechanics feedback}

- This tool could be used as a monitoring system to track progress or provide feedback to the musician, student or teacher.

\section{Ergonomic considerations}

- Sourcing instrument-specific ergonomic modifications to aid the adaptation of the instrument to the musician. 
a graduated return to playing and/or return-to-work plan such that sufficient rest and recovery for any damaged neuromusculoskeletal structures. A practice diary could be used to record and monitor timing of playing and rest breaks, Additional strengthening, movement or flexibility regimes off the instrument into relevant ranges of motion, and muscle activation patterns specific for the instrumentalist (e.g., consider whether the strengthening needs to occur in inner/middle/outer range for the muscle/s with a which type of muscle contraction). Consideration of playing-related demands created by the instrument and the workplace may require additional management strategies (e.g., reduced rest week between multiple orchestral cycles with increased performances and difficulty of repertoire may require an onsite physical therapy recovery service to aid recovery and promptly manage any playing-related injuries).

In summary, emerging evidence in the field of music medicine has lead to useful insights and clinically applicable strategies for the management of PRMDs in musicians. Beyond a thorough understanding of current models of management of work-related musculoskeletal disorder, physical therapists should further tailor their history taking and physical assessment to treat musicians as a highly specialized and hyper-functioning population. Relevant education and advice should be provided to musicians early in their injury whilst preventative information needs to be delivered early and throughout their careers. Specific training and workplace demands must also be carefully considered in the comprehensive management of the musician's injuries. Finally, proactive steps at music institutions and organizations should be taken, such as implementing onsite health prevention and management services for musicians, as playing-related problems in this population is not only highly prevalent and persistent but can also become greatly debilitating ultimately jeopardize a musicians' career.

\section{AUTHOR CONTRIBUTIONS}

Cliffton Chan and Bronwen Ackermann made substantial contributions to the conception and design of this work, drafting the work and revising it critically for important intellectual content. We give permission for this paper to be published and agree to be accountable for all aspects of the work in ensuring that questions related to the accuracy or integrity of any part of the work are appropriately investigated and resolved.

\section{ACKNOWLEDGMENTS}

Cliffton Chan and Bronwen Ackermann would like to thank the Australian Research Council, Australian Council of the Arts and the eight participating orchestras (Australian Opera and Ballet Orchestra, Sydney Symphony, Melbourne Symphony Orchestra, Orchestra Victoria, Adelaide Symphony Orchestra, Queensland Symphony Orchestra, Tasmanian Symphony Orchestra, West Australian Symphony Orchestra; LP0989486) for funding and supporting the "Sound Practice" project. The authors would also like to acknowledge the useful feedback provided by Dr. Debra Shirley during the write-up of this paper.

\section{REFERENCES}

Ackermann, B. (2002). Managing the musculoskeletal health of musicians on tour. Med. Probl. Perform. Art. 7, 63-67.

Ackermann, B., Adams, R. D., and Marshall, E. (2002). Strength or endurance training for undergraduate music majors at a university? Med. Probl. Perform. Art. 17, 33-41.

Ackermann, B. J. (2010). "Therapeutic management of the injured musician," in Performing Arts Medicine, eds R. Sataloff, A. Brandfonbrener, and R. Lederman (Narberth, PA: Science \& Medicine), 247-270.

Ackermann, B. J., and Adams, R. D. (2004). Perceptions of causes of performancerelated injuries by music health experts and injured violinists 1. Percept. Mot. Skills 99, 669-678. doi: 10.2466/PMS.99.6.669-678

Ackermann, B. J., Driscoll, T., and Kenny, D. T. (2012). Musculoskeletal pain and injury in professional orchestral musicians in Australia. Med. Probl. Perform. Art. $27,181$.

Ainscough-Potts, A., Morrissey, M., and Critchley, D. (2006). The response of the transverse abdominis and internal oblique muscles to different postures. Man. Ther. 11, 54-60. doi: 10.1016/j.math.2005.03.007

Altenmüller, E., and Jabusch, H. C. (2010). Focal dystonia in musicians: phenomenology, pathophysiology and triggering factors. Eur. J. Neurol. 17(Suppl. 1), 31-36. doi: 10.1111/j.1468-1331.2010.03048.x

Andersen, L., Andersen, C., Mortensen, O., Poulsen, O., Bjørnlund, I., and Zebis, M. (2010a). Muscle activation and perceived loading during rehabilitation exercises: comparison of dumbbells and elastic resistance. Phys. Ther. 90, 538-549. doi: 10.2522/ptj.20090167

Andersen, L., Christensen, K., Holterman, A., Poulsen, O., Sjøgaard, G., Pedersen, M., et al. (2010b). Effect of physical exercise interventions on musculoskeletal pain in all body regions among office workers: a one-year randomized controlled trial. Man. Ther. 15, 100-104. doi: 10.1016/j.math.2009.08.004

Andersen, L., Andersen, C., Zebis, M., Neilsen, P., Søgaard, K., and Sjøgaard, G. (2008). Effect of physical training on function of chronically painful muscles: a randomized controlled trial. J. Appl. Physiol. 105, 1796-1801. doi: 10.1152/japplphysiol.91057.2008

Äng, B., Monnier, A., and Harms-Ringdahl, K. (2009). Neck/shoulder exercise for neck pain in air force helicopter pilots: a randomized controlled trial. Spine 34, E544-E551. doi: 10.1097/BRS.0b013e3181aa6870

Argus, C., Gill, N., Keogh, J., and Hopkins, W. (2011). Acute effects of verbal feedback on upper-body performance in elite athletes. J. Strength Cond. Res. 25, 3282-3287. doi: 10.1519/JSC.0b013e3182133b8c

Australia SJsA. (2012). Sprains and Strains. Available at: http://stjohn.org.au/assets/ uploads/fact\%20sheets/english/FS_sprains.pdf

Baldwin, M. L. (2004). Reducing the costs of work-related musculoskeletal disorders: targeting strategies to chronic disability cases. J. Electromyogr. Kinesiol. 14, 33-41. doi: 10.1016/j.jelekin.2003.09.013

Baranowski, T., Cerin, E., and Baranowski, J. (2009). Steps in the design, development and formative evaluation of obesity prevention-related behavior change trials. Int. J. Behav. Nutr. Phys. Act. 6, 6. doi: 10.1186/1479-5868-6-6

Barrowcliffe, K. D. (1999). The Knowledge of Playing-Related Injuries Among University Music Teachers. Ph.D thesis, The University of Western Ontario, London, ON.

Bell, J. A., and Burnett, A. (2009). Exercise for the primary, secondary and tertiary prevention of low back pain in the workplace: a systematic review. J. Occup. Rehabil. 19, 8-24. doi: 10.1007/s10926-009-9164-5

Blangsted, A., Sogaard, K., Hansen, E., Hannerz, H., and Sjogaard, G. (2008). One-year randomized controlled trial with different physical-activity programs to reduce musculoskeletal symptoms in the neck and shoulders among office workers. Scand. J. Work Environ. Health 34, 55-65. doi: 10.5271/sjweh.1192

Blum, J. (2003). Examination and interface with the musician. Hand Clin. 19, 223-230. doi: 10.1016/S0749-0712(02)00097-5

Bohr, P. C. (2002). Office ergonomics education: a comparison of traditional and participatory methods. Work 19, 185-191.

Boocock, M. G., McNair, P. J., Larmer, P. J., Armstrong, B., Collier, J., Simmonds, M., et al. (2007). Interventions for the prevention and management of neck/upper extremity musculoskeletal conditions: a systematic review. Occup. Environ. Med. 64, 291-303. doi: 10.1136/oem.2005.025593

Booth, F., Roberts, C., and Laye, M. (2012). Lack of exercise is a major cause of chronic diseases. Compr. Physiol. 2, 1143-1211. doi: 10.1002/cphy. c110025 
Bragge, P., Bialocerkowski, A., and McMeeken, J. (2006). Understanding playingrelated musculoskeletal disorders in elite pianists: a grounded theory study. Med. Probl. Perform. Art. 21, 7179.

Brandfonbrener, A. (1997). Orchestral injury prevention intervention study. Med. Probl. Perform. Art. 12, 9-14.

Brandfonbrener, A. (2010). "Etiologies of medical problems in performing artists," in Performing Arts Medicine, 3rd Edn, eds R. Sataloff, A. Brandfonbrener, and R. Lederman (Narberth, PA: Science \& Medicine), 25.

Briggs, A., van Dieën, J., Wrigley, T., Greig, A., Phillips, B., Lo, S., et al. (2007). Thoracic kyphosis affects spinal loads and trunk muscle force. Phys. Ther. 87, 595-607. doi: 10.2522/ptj.20060119

Bruckner, P., and Khan, K. (2012). "Sports injuries: acute," in Clinical Sports Medicine, eds P. Bruckner and K. Khan (North Ryde, NSW: McGraw-Hill), $15-24$.

Cailliet, R. (1990). Abnormalities of the sitting postures of musicians. Med. Probl. Perform. Art. 5, 131-135.

Campbell, B., Kreider, R., Ziegenfuss, T., Roberts, M., Burke, D., Landis, J., et al. (2007). International society of sports nutrition position stand: protein and exercise. J. Int. Soc. Sports Nutr. 4, 1-7. doi: 10.1186/1550-2783-4-8

Chadefaux, D., Wanderley, M., Le Carrou, J., Fabre, B., and Daudet, L. (eds). (2012) "Experimental study of the musician/instrument interaction in the case of the concert harp," in Proceedings of the Acoustics 2012, Nantes.

Chaffin, D., Andersson, G., and Martin, B. (1991). Occupational Biomechanics. New York, NY: Wiley .

Chan, C., Driscoll, T., and Ackermann, B. (2013a). "Can experienced observers detect postural changes in professional orchestral musicians after interventions?" in International Symposium on Performance Science, eds A. Williamon and W. Goebl (Vienna: European Association of Conservatories), 181-186.

Chan, C., Driscoll, T., and Ackermann, B. J. (2013b). Development of a specific exercise programme for professional orchestral musicians. Inj. Prev. 19, 257-263. doi: 10.1136/injuryprev-2012-040608

Chan, C., Driscoll, T., and Ackermann, B. J. (2013c). The usefulness of on-site physical therapy-led triage services for professional orchestral musicians - a national cohort study. BMC Musculoskelet. Disord. 14:98. doi: 10.1186/1471-2474-14-98

Chan, C., Driscoll, T., and Ackermann, B. (2014a). Exercise DVD effect on musculoskeletal disorders in professional orchestral musicians. Occup. Med. 64, 23-30. doi: $10.1093 /$ occmed/kqt117

Chan, C., Driscoll, T., and Ackermann, B. (2014b). The effect of a musicians' exercise intervention on performance-related musculoskeletal disorders. Med. Probl. Perform. Art. 64, 23-30.

Chimenti, R. L., Van Dillen, L. R., Prather, H., Hunt, D., Chimenti, P. C., and Khoo-Summers, L. (2013). Underutilization of worker's compensation insurance among professional orchestral musicians. Med. Probl. Perform. Art. 28, 54-60.

Claus, A., Hides, J., Moseley, G., and Hodges, P. (2009). Is “ideal” sitting posture real?: Measurement of spinal curves in four sitting postures. Man. Ther. 14, 404-408. doi: 10.1016/j.math.2008.06.001

da Costa, B. R., and Viera, E. R. (2010). Risk factors for work-related musculoskeletal disorders: a systematic review of recent longitudinal studies. Am. J. Ind. Med. 53 285-323. doi: 10.1002/ajim.20750

Davies, J., and Mangion, S. (2002). Predictors of pain and other musculoskeletal symptoms among professional instrumental musicians: elucidating specific effects. Med. Probl. Perform. Art. 17, 155-168.

de Greef, M., van Wijck, R., Reynders, K., Toussaint, J., and Hesseling, R. (2003). Impact of the Groningen exercise therapy for symphony orchestra musicians program on perceived physical competence and playing-related musculoskeletal disorders of professional musicians. Med. Probl. Perform. Art. 18, 156-160.

Dehar, M.-A., Casswell, S., and Duignan, P. (1993). Formative and process evaluation of health promotion and disease prevention programs. Eval. Rev. 17, 204-220. doi: 10.1177/0193841X9301700205

Dommerholt, J. (2009). Performing arts medicine - instrumentalist musicians Part I - General considerations. J. Bodyw. Mov. Ther. 13, 311-319. doi: 10.1016/j.jbmt.2009.02.003

Dommerholt, J. (2010). Performing arts medicine - instrumentalist musicians: Part III - case histories. J. Bodyw. Mov. Ther. 14, 127-138. doi 10.1016/j.jbmt.2009.02.005

Donovan, J. J., and Radosevich, D. J. (1999). A meta-analytic review of the distribution of practice effect: now you see it, now you don't. J. Appl. Psychol. 84, 795-805. doi: $10.1037 / 0021-9010.84 .5 .795$
Drawer, S., and Fuller, C. W. (2001). Propensity for osteoarthritis and lower limb joint pain in retired professional soccer players. Br. J. Sports Med. 25, 402-408. doi: 10.1136/bjsm.35.6.402

Driscoll, T., and Ackermann, B. (2012). Applied musculoskeletal assessment: results from a standardised physical assessment in a national population of professional orchestral musicians. Rheumatology S2, 1-7.

Edling, C., and Fjellman-Wiklund, A. (2009). Musculoskeletal disorders and asymmetric playing postures of the upper extremity and back in music teachers: a pilot study. Med. Probl. Perform. Art. 24, 113-118.

Eijsden-Besseling, M., Kuijers, M., Kap, B., Stam, H., and Terpstra-Lindeman, E. (1993). Difference in posture and postural disorders between music and medical students. Med. Probl. Perform. Art. 8, 110.

Fernandes, L., and de Barros, R. (2012). Grip pattern and finger coordination differences between pianists and non-pianists. J. Electromyogr. Kinesiol. 22, 412418. doi: 10.1016/j.jelekin.2012.02.007

Fletcher, S. D. (2008). The Effect of Focal Task-Specific Embouchure Dystonia Upon Brass Musicians: A Literature Review and Case Study. Ann Arbor, MI: ProQuest.

Foxman, I., and Burgel, B. (2006). Musician health and safety: preventing playing-related musculoskeletal disorders. AAOHN J. 54, 309-316.

Fransen, M., and McConnnell, S. (2008). Exercise for osteoarthritis of the knee. Cochrane Database Syst. Rev. CD004376. doi: 10.1002/14651858.CD004376.pub2

Freivalds, A. (2011). Biomechanics of the Upper Limbs: Mechanics, Modeling, and Musculoskeletal Injuries. Boca Raton, FL: Taylor \& Francis .

Frucht, S. J. (2009). Embouchure dystonia - portrait of a task-specific cranial dystonia. Mov. Disord. 24, 1752-1762. doi: 10.1002/mds.22550

Fry, H. J. H. (2000). “Overuse syndrome," in Medical Problems of the Instrumentalist Musician, eds R. Tubiana and P. C. Amadio (London: Martin Dunitz), 245-271. doi: 10.1201/b14694-13

Gatchel, R., Polatin, P., Noe, C., Gardea, M., Pulliam, C., and Thompson, J. (2003). Treatment and cost-effectiveness of early intervention for acute lowback pain patients: a one-year prospective study. J. Occup. Rehabil. 13, 1-9. doi: 10.1023/A:1021823505774

Gaunt, H. (2004). Breathing and the oboe: playing, teaching and learning. Br. J. Music Edu. 21, 313-328. doi: 10.1017/S0265051 704005819

Gerg, M., and Smith, S. (2008). Training the "industrial athlete" - developing jobspecific exercise programs to reduce injuries. OT Pract. 13, CE1-CE7.

Green, J. A., Chamagne, P., and Tubiana, R. (2000). “Prevention,” in Medical Problems of the Instrumentalist Musician, eds R. Tubiana and P. C. Amadio (London: Martin Dunitz), 531-557. doi: 10.1201/b14694-30

Guptill, C. A. (2011). The lived experience of professional musicians with playingrelated injuries: a phenomenological inquiry. Med. Probl. Perform. Art. 26, 84-95.

Guptill, C. A. (2012). Injured professional musicians and the complex relationship between occupation and helth. J. Occup. Sci. 19, 258-270. doi: 10.1080/14427591.2012.670901

Harding, K., Taylor, N., and Shaw-Stuart, L. (2009). Triaging patients for allied health services: a systematic review of the literature. Br. J. Occup. Ther. 72, 153-162.

Haslegrave, C. (1994). What do we mean by a 'working posture'?. Ergonomics 37, 781-799. doi: 10.1080/00140139408963688

Hedman, T., and Fernie, G. (1997). Mechanical response of the lumbar spine to seated postural loads. Spine 22, 734-743. doi: 10.1097/00007632-19970401000004

Hides, J. (2004). Paraspinal Mechanism and Support of the Lumbar Spine. Therapeutic Exercise for Lumbopelvic Stabilisation: A Motor Control Approach for the Treatment and Prevention of Low Back Pain, 2nd Edn. Edinburgh: Churchill Livingstone.

Hoenig, K., Müller, C., Hermberger, B., Sim, E.-J., Spitzer, M., Ehret, G., etal. (2011). Neuroplasticity of semantic representations for musical instruments in professional musicians. Neuroimage 56, 1714-1725. doi: 10.1016/j.neuroimage.2011.02.065

Hoogendoorn, W., Bongers, P. M., de Vet, H., Douwes, M., Koes, B., Miedema, M., et al. (2000). Flexion and rotation of the trunk and lifting at work are risk factors for low back pain: results of a prospective cohort study. Spine 25, 3087-3092. doi: 10.1097/00007632-200012010-00018

Holt, W. (1993). Nutrition and athletes. Am. Fam. Phys. 47, 1757-1764.

Hoppmann, R. A. (2010). "Musculoskeletal problems of instrumental musicians," in Performing Arts Medicine, 3rd Edn, eds R. Sataloff, A. Brandfonbrener, and R. Lederman (Narberth, PA: Science \& Medicine, Inc.), 207-228. 
Hoppmann, R. A., and Patrone, N. A. (1989). A review of musculoskeletal problems in instrumental musicians. Semin. Arthritis Rheum. 19, 117-126. doi: 10.1016/0049-0172(89)90056-5

Huang, G. D., and Feuerstein, M. (2004). Identifying work organization targets for a work-related musculoskeletal symptom prevention program. J. Occup. Rehabil. 14, 13-30. doi: 10.1023/B:JOOR.0000015008.25177.8b

Hupperets, M., Verhagen, E., and van Mechelen, W. (2009). Effect of unsupervised home based proprioceptive training on recurrences of ankle sprain: randomised controlled trial. BMJ 339, b2684. doi: 10.1136/bmj.b2684

Hyde, K., Lerch, J., Norton, A., Forgeard, M., Winner, E., Evans, A., et al. (2009). Musical training shapes structural brain development. J. Neurosci. 29, 3019-3025. doi: 10.1523/JNEUROSCI.5118-08.2009

Iltis, P. W., and Givens, M. W. (2005). EMG characterization of embouchure muscle activity: reliability and application to embouchure dystonia. Med. Probl. Perform. Art. 20, 25-34.

Järvinen, T., Järvinen, T., Kääriäinen, M., Ä̈rimaa, V., Vaittinen, S., and Kalimo, H. (2007). Muscle injuries: optimising recovery. Best Pract. Res. Clin. Rheumatol. 21 317-331. doi: 10.1016/j.berh.2006.12.004

Jéquier, E., and Constant, F. (2010). Water as an essential nutrient: the physiological basis of hydration. Eur. J. Clin. Nutr. 64, 115-123. doi: 10.1038/ejcn.2009.111

Jurg, M. E., De Meij, J. S., Van der Wal, M. F., and Koelen, M. A. (2008). Using health promotion outcomes in formative evaluation studies to predict success factors in interventions: an application to an intervention for promoting physical activity in Dutch children (JUMP-in). Health Promot. Int. 23, 231-239. doi: 10.1093/heapro/dan008

Kannus, P., Parkkari, J., Järvinen, T., Järvinen, T., and Järvinen, M. (2003). Basic science and clinical studies coincide: active treatment is needed after a sports injury. Scand. J. Med. Sci. Sports 13, 150-154. doi: 10.1034/j.1600-0838.2003. 02225.x

Kapandji, A. (2000). "Anatomy of the Spine," in Medical Problems of the Instrumentalist Musician, eds R. Tubiana and P. C. Amadio (London: Martin Dunitz), 55-68. doi: 10.1201/b14694-4

Kava, K., Larson, C., Stiller, C., and Maher, S. (2010). Trunk endurance exercise and the effect in instrumental performance: a preliminary study comparing Pilates exercise and a trunk and proximal upper extremity endurance exercise program. Music Perform. Res. 3, 1-30.

Kay, T., Gross, A., Goldsmith, C., Santaguida, P., Hoving, J., and Bronfort, G. (2005). Exercises for mechanical neck disorders. Cochrane Database Syst. Rev. CD004250. doi: 10.1002/14651858.CD004250.pub3

Kelleher, L., Campbell, K., and Dickey, J. (2013). Biomechanical research on bowed string musicians. Med. Probl. Perform. Art. 28, 212-218.

Keller, P. E. (2012). Mental imagery in music performance: underlying mechanisms and potential benefits. Ann. N. Y. Acad. Sci. 1252, 206-213. doi: 10.1111/j.17496632.2011.06439.x

Kendall, H., Kendall, F., and Boynton, D. (1952). Posture and Pain. Baltimore: Williams \& Wilkins

Kenefick, R., and Sawka, M. (2007). Hydration at the work site. J. Am. Coll. Nutr. 26(Suppl. 5), 597S-603S. doi: 10.1080/07315724.2007. 10719665

Kennedy, C., Amick, B. III, Dennerlein, J., Brewer, S., Catli, S., Williams, R., et al. (2010). Systematic review of the role occupational health and safety interventions in the prevention of upper extremity musculoskeletal symptoms, signs, disorders injuries, claims and lost time. J. Occup. Rehabil. 20, 127-162. doi: 10.1007/s10926009-9211-2

Kenny, D., and Ackermann, B. (2013). Performance-related musculoskeletal pain, depression and music performance anxiety in professional orchestral musicians: a population study. Psychol. Music 1-18. doi: 10.1177/0305735613493953

Kera, T., and Maruyama, H. (2005). The effect of posture on respiratory activity of the abdominal muscles. J. Physiol. Anthropol. Appl. Hum. Sci. 24, 259-265. doi: 10.2114/jpa.24.259

Khalil, H., Quinn, L., van Deursen, R., Martin, R., Rosser, A., and Busse, M. (2012). Adherence to use of a home-based exercise DVD in people with Huntington disease: participants' perspectives. Phys. Ther. 92, 69-82. doi: 10.2522/ptj.20100438

Kolt, G. S., and Snyder-Mackler, L. (2007). "The role of the physical therapies in sport, exercise, and physical activity," in Physical Therapies in Sport and Exercise, 2nd Edn, eds G. S. Kolt and L. Snyder-Mackler (Edinburgh: Churchill Livingstone), $1-5$.
Krause, V., Scnitzler, A., and Pollok, B. (2010). Functional network interactions during sensorimotor synchronization in musicians and non-musicians. Neuroimage 52, 245-251. doi: 10.1016/j.neuroimage.2010.03.081

Kumar, S. (2001). Theories of musculoskeletal injury causation. Ergonomics 44, 17-47. doi: 10.1080/00140130120716

Kumar, V., Atherton, P., Smith, K., and Rennie, M. (2009). Human muscle protein synthesis and breakdown and after exercise. J. Appl. Physiol. 106, 2026-2039. doi: 10.1152/japplphysiol.91481.2008

Laisné, F., Lecomte, C., and Corbière, M. (2012). Biopsychosocial predictors of prognosis in musculoskeletal disorders: a systematic review of the literature. Disabil. Rehabil. 34, 1912-1941. doi: 10.3109/09638288.2012.729362

Landers, M., Barker, G., Wallentine, S., McWhorter, J., and Peel, C. (2003). A comparison of tidal volume, breathing frequency, and minute ventilation between two sitting postures in healthy adults. Physiother. Theory Pract. 19, 109-119. doi: 10.1080/09593980307958

Leaver, R. E., Harris, E. C., and Palmer, K. T. (2011). Musculoskeletal pain in elite professional musicians from British symphony orchestras. Occup. Med. 61, 549-555. doi: 10.1093/occmed/kqr129

Lee, T. D., and Wishart, L. R. (2005). Motor learning conundrums (and possible solutions). Quest 57,67-78. doi: 10.1080/00336297.2005.10491843

Lees, A. (2002). Technical analysis in sport: a critical review. J. Sports Sci. 20, 813-828. doi: 10.1080/026404102320675657

Linton, S. (2002). Early identification and intervention in the prevention of musculoskeletal pain. Am. J. Ind. Med. 41, 433-442. doi: 10.1002/ajim.10052

Lysaght, R., Donnelly, C., and Luong, D. (2010). Best practices in the rehabilitation of acute musculoskeletal disorders in workers with injuries: an integrative review and analysis of evolving trends. Work 35, 319-333. doi: 10.3233/WOR2010-0993

Macedo, L., Maher, C., Latimer, J., and McAuley, J. (2009). Motor control exercise for persistent, nonspecific low back pain: a systematic review. Phys. Ther. 89, 9-25. doi: $10.2522 /$ ptj.20080103

Machotka, Z., Kumar, S., and Perraton, L. (2009). A systematic review of the literature on the effectiveness of exercise therapy for groin pain in athletes. Sports Med. Arthrosc. Rehabil. Ther. Technol. 1, 5. doi: 10.1186/1758-2555-1-5

Magnusson, M., and Pope, M. (1998). A review of the biomechanics and epidemiology of working postures (it isn't always vibration which is to blame!). J. Sound Vib. 215, 965-976. doi: 10.1006/jsvi.1998.1677

Manore, M., Meyer, N., and Thompson, J. (2009). Sport Nutrition for Health and Performance, 2nd Edn. Champaign, IL: Human Kinetics .

McGinnis, P. (2013). Biomechanics of Sport and Exercise, 3rd Edn. Champaign, IL: Human Kinetics.

Medicine ACoS. (2010). ACSM's Guidelines for Exercise Testing and Prescription, 8th Edn, ed. W. Thompson (Philadelphia: Lippincott, Williams \& Wilkins).

Medoff, L. (1999). The importance of movement education in the training of young violinists. Med. Probl. Perform. Art. 14, 210-219.

Menuhim, Y. (1986). The Complete Violinist. New York: Summit Books.

Middlestadt, S., and Fishbein, M. (1989). The prevalence of severe musculoskeletal problems among male and female symphony orchestra string players. Med. Probl. Perform. Art. 4, 41-48.

Milanese, S. (2000). Provision of on-site physiotherapy services during the performance of Wagner's ring cycle by the Adelaide Symphony Orchestra. Med. Probl. Perform. Art. 15, 107-110.

Montain, S. (2008). Hydration recommendations for sport 2008. Curr. Sports Med. Rep. 7, 187-192. doi: 10.1249/JSR.0b013e31817f005f

Nash, C. E., Mickan, S. M., Del Mar, C. B., and Glasziou, P. P. (2004). Resting injured limbs delays recovery: a systematic review. J. Fam. Pract. 53, 706-712.

Newmark, J., and Lederman, R. (1987). Practice doesn't necessarily make perfect: incidence of overuse syndromes in amateur instrumentalists. Med. Probl. Perform. Art. 2, 142-144.

Norris, R. (1993). The Musician's Survival Manual: A Guide to Preventing and Treating Injuries in Instrumentalists. St. Louis, MO: International Conference of Symphony and Opera Musicians, 134.

Nyman, T., Wiktorin, C., Mulder, M., and Johansson, Y. (2007). Work postures and neck-shoulder pain among orchestra musicians. Am. J. Ind. Med. 50, 370-376. doi: 10.1002/ajim.20454

Orchard, J., and Best, T. M. (2002). The mangament of muscle strain injuries: an early return versus the risk of recurrence. Clin. J. Sport Med. 12, 3-5. doi: 10.1097/00042752-200201000-00004 
O'Sullivan, K., O'Sullivan, P., O'Sullivan, L., and Dankaerts, W. (2012). What do physiotherapists consider to be the best sitting spinal posture? Man. Ther. 17, 432-437. doi: 10.1016/j.math.2012.04.007

O’Sullivan, P., Grahamslaw, K., Kendell, M., Lapenskie, S., Möller, N., and Richards, K. (2002). The effect of different standing and sitting postures on trunk muscle activity in a pain-free population. Spine 27, 1238-1244. doi: 10.1097/00007632200206010-00019

Paarup, H. M., Baelum, J., Holm, J. W., Manniche, C., and Wedderkopp, N. (2011). Prevalence and consequences of musculoskeletal symptoms in symphony orchestra musicians vary by gender: a cross-sectional study. BMC Musculoskelet. Disord. 12:223. doi: 10.1186/1471-2474-12-223

Pascarelli, E. F., and Hsu, Y.-P. (2001). Understanding work-related upper extremity disorders: clinical findings in 485 computer users, musicians, and others. J. Occup. Rehabil. 11, 1-21. doi: 10.1023/A:101664 7923501

Pemoff, A., Alegri, C., Sicardi, M., Blanchentiere, H., Balan, S., Gitard, M., et al. (2012). Upper limb injuries in Argentine musicians. J. Bone Joint Surg. 94(Suppl. 37), 315.

Phillips, E., Farrow, D., Ball, K., and Helmer, R. (2013). Harnessing and understanding feedback technology in applied settings. Sports Med. 43, 919-925. doi: 10.1007/s40279-013-0072-7

Phillips, S. (2006). Dietary protein for athletes: from requirements to metabolic advantage. Appl. Physiol. Nutr. Metab. 31, 647-654. doi: 10.1139/ h06-035

Pink, M. M., and Tibone, J. E. (2000). The painful shoulder in the swimming athlete. Orthop. Clin. North Am. 31, 247-261. doi: 10.1016/S0030-5898(05) 70145-0

Popkin, B., D’Anci, K., and Rosenberg, I. (2010). Water, hydration, and health. Nutr. Rev. 68, 439-458. doi: 10.1111/j.1753-4887.2010. 00304.x

Popovich, R. M., Gardner, J. W., Potter, R., Knapik, J. J., and Jones, B. H. (2000). Effect of rest from running on overuse injuries in Army basic training. Am. J. Prev. Med. 18, 147-155. doi: 10.1016/S0749-3797(99) 00167-1

Price, K., and Watson, A. (2011). Postural problems of the left shoulder in an orchestral trombonist. Work 40,317-324. doi: 10.3233/WOR-2011-1238

Quarrier, N., and Stenback, J. (2002). Considerations for treating the musician. Orthop. Pract. 14, 8-10.

Ratnovsky, A., Elad, D., and Halpern, P. (2008). Mechanics of respiratory muscles. Resipir. Physiol. Neurobiol. 163, 82-89. doi: 10.1016/j.resp.2008.04.019

Raymond, D. M. III, Romeo, J. H., and Kumke, K. V. (2012). A pilot study of occupational injury and illness experienced by classical musicians. Workplace Health Saf. 60, 19-24. doi: 10.3928/2165079920111227-01

Rickert, D. L., Barrett, M. S., and Ackermann, B. (2013). Injury and the orchestral environment: Part I. Med. Probl. Perform. Art. 28, 219-229.

Robertson, E. M., Pascual-Leone, A., and Miall, R. C. (2004). Current concepts in procedural consolidation. Nat. Rev. Neurosci. 5, 576-582. doi: 10.1038/ nrn1426

Robinson, D., and Zander, J. (2002). Preventing Musculoskeletal Injuries (MSI) for Musicians and Dancers: A Resource Guide. Vancouver: Safety and Health in Arts Production and Entertainment.

Roset-Llobet, J., Rosinés-Cubells, D., and Saló-Orfila, J. (2000). Identification of risk factors for musicians in Catalonia (Spain). Med. Probl. Perform. Art. 15, 167-173.

Roussos, C. (1985). Function and fatigue of respiratory muscles. Chest J. 88(Suppl. 2),124S-132S. doi: 10.1378/chest.88.2_Supplement.124S

Schoeb, V., and Zosso, A. (2012). "You cannot perform music without taking care of your body": a qualitative study on musicians' representation of body and health. Med. Probl. Perform. Art. 27, 129-136.

Shafer-Crane, G. A. (2006). Repetitive stress and strain injuries: preventive exercises for the musician. Phys. Med. Rehabil. Clin. North Am. 17, 827-842. doi: 10.1016/j.pmr.2006.07.005

Shirreffs, S. (2009). Hydration in sport and exercise: water, sports drinks and other drinks. Nutr. Bull. 34, 374-379. doi: 10.1111/j.1467-3010.2009. 01790.x

Silverstein, B., and Clark, R. (2004). Interventions to reduce work-related musculoskeletal disorders. J. Electromyogr. Kinesiol. 14, 135-152. doi: 10.1016/j.jelekin.2003.09.023
Spahn, C., Hildebrandt, H., and Seidenglanz, K. (2001). Effectiveness of a prophylactic course to prevent playing-related health problems of music students. Med. Probl. Perform. Art. 16, 24-31.

Stetler, C. B., Legro, M. W., Wallace, C. M., Bowman, C., Guihan, M., Hagedorn, H., et al. (2006). The role of formative evaluation in implementation research and the QUERI experience. J. Gen. Intern. Med. 21, S1-S8. doi: 10.1007/s11606-0060267-9

Stucki, G., Stier-Jarmer, M., Grill, E., and Melvin, J. (2005). Rationale and principles of early rehabilitation care after an acute injury or illness. Disabil. Rehabil. 27, 353-359. doi: 10.1080/09638280400014105

Sung, K., Chang, J., Freivalds, A., and Kong, Y. (2013). "Development of the two-dimensional biomechanical hand model for a guitar player," in Proceedings of the Human Factors and Ergonomics Society Annual Meeting (New York: SAGE Publications), 1653-1657. doi: 10.1177/15419312 13571367

Tubiana, R. (2000). "Functional anatomy," in Medical Problems of the Instrumentalist Musician, eds R. Tubiana and P. C. Amadio (London: Martin Dunitz), 1-4. doi: 10.1201/b14694-2

Vandelanotte, C., and Mummery, W. (2011). Qualitative and quantitative research into the development and feasibility of a video-tailored physical activity intervention. Int. J. Behav. Nutr. Phys. Act. 8, 70. doi: 10.1186/1479$5868-8-70$

van Eijsden, M., Gerhards, S., de Bie, R., and Severens, J. (2009). Costeffectiveness of postural exercise therapy versus physiotherapy in computer screen-workers with early non-specific work-related upper limb disorders (WRULD); a randomized controlled trial. Trials 10, 103. doi: 10.1186/1745-621510-103

Van Hees, O. (ed.). (1997). "Physical exercise as prevention for musculoskeletal problems in musicians: a panacee demasque," in Proceedings of Health and the Musician Conference (New York: British Performing Arts Medicine Trust), A1.20A1.30.

Verhagen, A., Karels, C., Bierma-Zeinstra, S., Feleus, A., Dahaghin, S., Burdorf, A., et al. (2007). Exercise proves effective in a systematic review of work-related complaints of the arm, neck, or shoulder. J. Clin. Epidemiol. 60, 110-e1. doi: 10.1016/j.jclinepi.2006.05.006

Viera, E. R., and Kumar, S. (2004). Working postures: a literature review. J. Occup. Rehabil. 14, 143-159. doi: 10.1023/B:JOOR.0000018330. 46029.05

Vina, J., Sanchis-Gomar, F., Martinez-Bello, V., and Gomez-Cabrera, M. (2012). Exercise acts as a drug; the pharmacological benefits of exercise. Br. J. Pharmacol. 167, 1-12. doi: 10.1111/j.1476-5381.2012.01970.x

Visentin, P., Shan, G., and Wasiak, E. (2008). Informing music teaching and learning using movement analysis technology. Int. J. Music Edu. 26, 73-87. doi: $10.1177 / 0255761407085651$

Waivenhaus, F., Fox, A. J., Chaudhury, S., and Rodeo, S. A. (2012). Epidemiology of injuries and prevention strategies in competitive swimmers. Sports Health 4, 246-251. doi: 10.1177/1941738112442132

Watson, A. (2006). What can studying musicians tell us about motor control of the hand? J. Anatomy 208, 527-542. doi: 10.1111/j.1469-7580.2006. 00545.x

Weerapong, P., and Kolt, G. (2005). The mechanisms of massage and effects on performance, muscle recovery and injury prevention. Sports Med. 35, 235-256. doi: 10.2165/00007256-200535030-00004

Westgaard, R. H., and Winkel, J. (1996). Guidelines for occupational musculoskeletal load as a basis for intervention: a critical review. Appl. Ergon. 27, 79-88. doi: 10.1016/0003-6870(95)00062-3

Wilke, C., Priebus, J., Biallas, B., and Froböse, I. (2011). Motor activity as a way of preventing musculoskeletal problems in string musicians. Med. Probl. Perform. Art. 26, 24-29.

World Confederation for Physical Therapy. (2011). Policy Statement: Description of Physical Therapy. London: WCPT.

Wu, S. J. (2007). Occupational risk factors for musculoskeletal disorders in musicians: a systematic review. Med. Probl. Perform. Art. 22, 43-51.

Wulf, G., Shea, C., and Lewthwaite, R. (2010). Motor skill learning and performance: a review of influential factors. Med. Edu. 44, 75-84. doi: 10.1111/j.1365-2923.2009.03421.x

Zaza, C. (1993). Prevention of musicians' playing-related health problems: rationale and recommendations for action. Med. Probl. Perform. Art. 8, 117-121. 
Zaza, C. (1994). Research-based prevention for musicians. Med. Probl. Perform. Art. 9, 3-6.

Zaza, C., and Farewell, V. T. (1997). Musicians' playing-related musculoskeletal disorders: an examination of risk factors. Am. J. Ind. Med. 32, 292-300. doi: 10.1002/(SICI)1097-0274(199709)32:3<292::AID-AJIM16>3.0.CO;2-Q

Zetterberg, C., Backlund, H., Karlsson, J., Werner, H., and Olsson, L. (1998). Musculoskeletal problems among male and female music students. Med. Probl. Perform. Art. 13, 160-166.

Conflict of Interest Statement: The authors declare that the research was conducted in the absence of any commercial or financial relationships that could be construed as a potential conflict of interest.
Received: 28 February 2014; accepted: 19 June 2014; published online: 08 July 2014. Citation: Chan C and Ackermann B (2014) Evidence-informed physical therapy management of performance-related musculoskeletal disorders in musicians. Front. Psychol. 5:706. doi: 10.3389/fpsyg.2014.00706

This article was submitted to Cognitive Science, a section of the journal Frontiers in Psychology.

Copyright (C) 2014 Chan and Ackermann. This is an open-access article distributed under the terms of the Creative Commons Attribution License (CC BY). The use, distribution or reproduction in other forums is permitted, provided the original author(s) or licensor are credited and that the original publication in this journal is cited, in accordance with accepted academic practice. No use, distribution or reproduction is permitted which does not comply with these terms. 